\title{
Business Case for Installing E85 at Retail Stations
}

In a business environment where there are up to four gas stations on every major intersection, it's hard for retailers to differentiate themselves from their competitors. One way station owners can distinguish themselves and make a profit is to add alternative fuels, such as E85 (85\% ethanol, $15 \%$ gasoline), to their product mix. When pricing and availability of the fuel are positive, adding E85 can be a profitable move that can position a station as "green."

Offering E85 allows stations to attract customers who already own one of the approximately 6 million flexible fuel vehicles (FFVs) currently on U.S. roadways. These drivers may be attracted to a station offering a regionally produced fuel that displaces imported petroleum. In addition, stations offering E85 can market themselves to the numerous federal, state, and fuel provider fleets that have been required to buy alternative fuel vehicles (AFVs) under federal regulations. Federal and fuel provider fleets, along with some state fleets, are also required to fill these AFVs with alternative fuels. While FFVs in regulated fleets represent a small portion of the FFVs on the road, they can often serve as anchors for a station's E85 sales and attract new customers seeking both fuel and non-fuel items.

To help retailers predict the success or failure of installing E85 at their stations, the National Renewable Energy Laboratory (NREL) published the "E85 Retail Business Case," a comprehensive report that outlines a model fueling station owners can use to determine whether E85 would be right for them. This model answers the following two key questions affecting the potential profitability of adding E85 to the station mix.

- What configuration has the highest potential profitability?

- What happens to the gross margin required to meet investment goals if the actual E85 sales, equipment costs, or maintenance and operating costs are significantly different than the assumptions?

\section{Model Highlights}

According to NREL's model, the most profitable scenario is converting an existing mid-grade tank to supply E85. Installing a new tank is the second most profitable

\section{Keys to Success}

When adding E85 to a station mix, retailers must consider:

- Potential E85 sales volume

- Equipment configuration

- E85 availability and pricing

- Potential increases in non-fuel sales

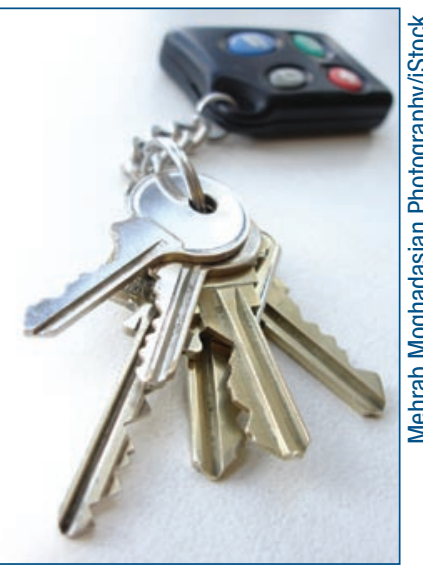

option, followed by converting the premium offering to E85. Order of profitability (mid-grade conversion, new tank, premium conversion) is not changed by halving or doubling any of the other variables. Within each configuration calculation, the throughput (i.e., the number of gallons of E85 sold) is the most important variable. In addition, even a small increase in non-fuel sales associated with an increase in traffic due to E85 fuel availability can make the project more profitable.

\section{Calculation Method}

NREL's model is based on discounted cash-flow analysisa standard protocol of assessing capital investments. It takes the initial investment, the terms of the loan, income, and operating costs into account.

To complete the cash-flow analysis, numerous baseline assumptions needed to be made. These assumptions were made after conducting interviews and literature reviews.

In its research, NREL found that the most significant variable in installing E85 infrastructure is throughput, or the number of E85 gallons sold. Since Minnesota has seen significant success with E85, NREL collected E85 sales information from the state's Department of Commerce. The throughput baseline used in the model is annual sales of 70,000 gallons of E85 per year, based on Minnesota sales statistics. In addition, the model assumes the equipment costs for adding E85 pumps are $\$ 20,000$ for a mid-grade tank conversion and $\$ 60,000$ for the installation of a new underground tank, based on information gathered from 


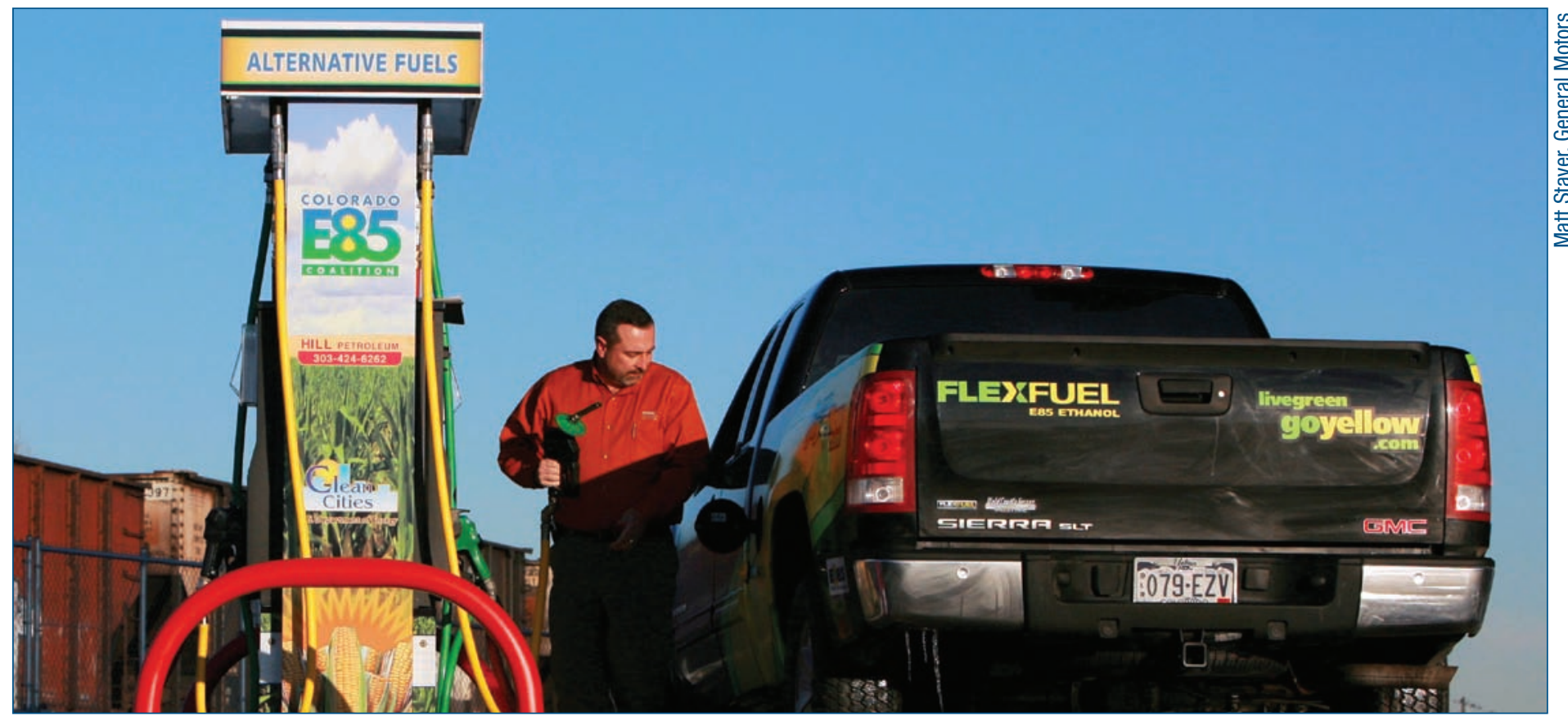

Offering E85 can help retailers increase sales by attracting new customers and fleets to their stations.

government agencies and fuel associations. Equipment configuration and upgrades considered in the model include:

- Mid-grade conversion: The retailer fills an existing tank with E85 after cleaning it and replacing or retrofitting non-compatible dispensers or equipment with compatible ones. This applies to cases where stations have a third tank for mid-grade that can be replaced by a blending valve, cases where stations have an extra unleaded tank, or cases where diesel or kerosene are replaced because their sales are deemed negligible.

- New tank: The retailer installs a new underground storage tank and retrofits or replaces dispensers, pumps, and piping with E85-compatible components. In this case, the retailer retains the sales of regular and premium fuel.

- Premium conversion: The retailer fills the premiumgrade tank with E85 after cleaning it and replacing noncompatible materials and components. This case applies to stations that blend their mid-grade rather than draw it from a designated mid-grade tank, so the retailer can no longer offer either mid- or premium-grade gasoline once the tank is converted. Therefore, lost revenue from both of these products is calculated.

Finally, the model estimates baseline maintenance and operation costs at $\$ 2,000$, based on interviews with equipment owners.

In addition to these parameters, the model requires numerous other inputs and assumptions related to other costs, funding, operations, depreciation, and taxes. For example, the model includes the federal infrastructure tax credit, which is outlined in Section 1342 of EPAct 2005 and is available through December 2009. This credit is for $30 \%$ of the infrastructure cost up to a maximum credit of $\$ 30,000$ per location. State infrastructure tax credits were not considered in the model. The analysis then calculated required margins when that all variables are halved and doubled to illustrate the effect of a range of costs and throughput.

\section{Results of Calculations}

When the model was used to run calculations with the baseline assumptions, the required gross margin on the E85 was \$.15 per gallon for the mid-grade conversion. Model runs using the $\$ 60,000$ estimate for installing a new underground tank calculated a required gross margin at $\$ .19$ per gallon, while converting the premium grade tank resulted in a required gross margin of $\$ .39$ per gallon.

To understand the impact on required gross margin when actual numbers are different than the assumptions, the analysis ran variables being independently halved and doubled. In every configuration scenario, the model showed that E85 throughput had the largest effect on the required gross margin.

Using the mid-grade conversion scenario, Figure 1 shows that by doubling E85 sales, the required margin was reduced from approximately $\$ .15$ per gallon to a little over $\$ .10$ per gallon. The same scenario shows that if the throughput estimate was halved, the required gross margin increased to almost $\$ .26$ per gallon. The effect of equipment cost is minimal; when the equipment costs were doubled, the required margin increased to a little more than \$.17. 


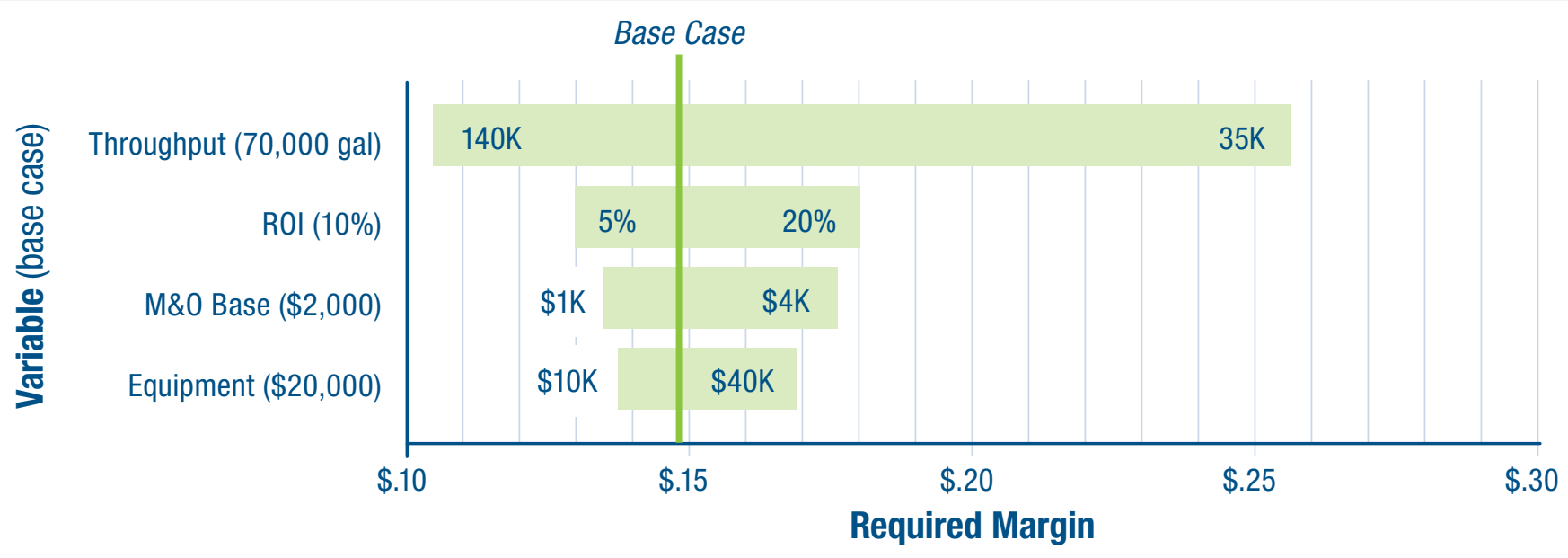

Figure 1. Effect on Required Margin of Halving and Doubling Baseline in Variables in the Mid-Grade Conversion Scenario

\section{Ensuring Success}

Because throughput is the most important variable, the first step toward ensuring success is determining that there is enough local demand for E85. Retailers must therefore estimate the number of E85-compatible FFVs garaged within a reasonable radius of their stations. Their local Clean Cities coordinator may have this information, as well as suggestions on area fleets looking for partnership opportunities. Station location, traffic flow, demographics, and other factors also significantly impact E85 demand.

\section{Baseline Assumptions}

- Required Return on Investment: 10\%

- Maintenance and Operating Costs: \$2,000/year

- E85 Sales: 70,000 gallons/year

- Equipment Upgrade Costs:

— New Tank: $\$ 60,000$

— Convert Existing Tank: $\$ 20,000$

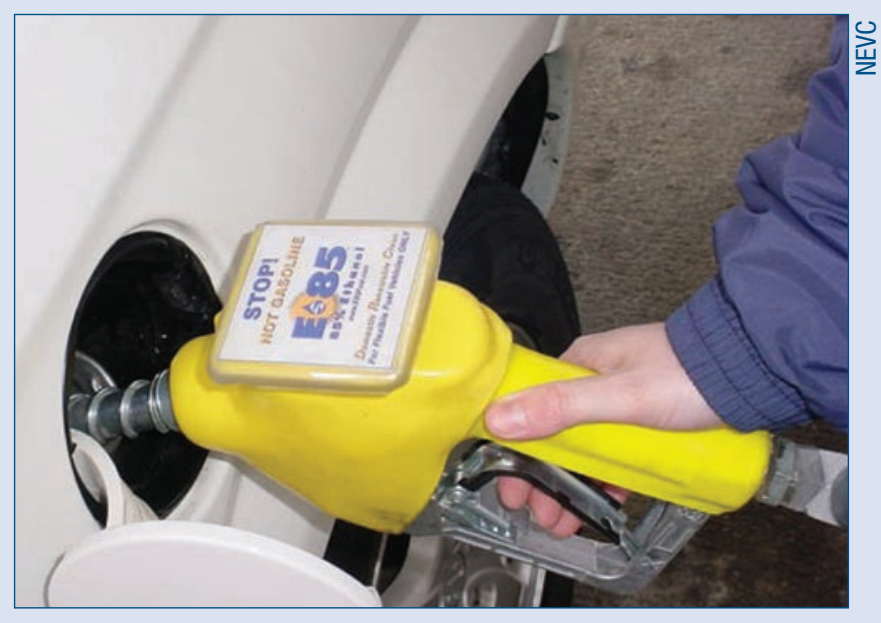

In a study of the Minnesota E85 market, * customer awareness was cited as the largest non-price factor influencing E85. Specifically, a road sign advertising E85 near one station increased sales by an average of $16 \%$. Not only can customer awareness be raised through signage, advertisements, and limited-time discounts, events such as grand openings are also effective. Clean Cities coordinators often help arrange grand opening events with high-profile speakers and media coverage.

To be successful, station owners must also keep an eye on the price of E85 relative to that of gasoline. In fact, the University of Minnesota study ${ }^{*}$ revealed that E85 sales dropped to nearly zero as the price differential between E85 and gasoline was reduced to zero. In addition, experienced owners of large retail chains find that their profits are maximized with a $20 \%$ price differential, ${ }^{* *}$ which is necessary to compensate drivers for more frequent fillups due to the reduced driving range of E85-fueled FFVs. To sell at this price differential, retailers must secure a dependable supply of E85 at a favorable wholesale price. One successful approach has been to secure long-term pricing and supply contracts with a local fuel blender/ dealer.

The NREL report also discusses increased sales of highermargin, non-fuel goods. Offering E85 can help increase these sales in two ways: It will attract new customers to your station, and these new customers will come back more often due to the reduced driving range of E85. Increased and more frequent traffic to the station could translate into increased sales of higher-margin goods.

* "What Determines Ethanol 85 Use? Learning from Minnesota's E85 Pilot Project," by L. Dobrovolny, University of Minnesota. 2005.

** "Marketer Discussion Session," presented by D. Mills and J. Gentry at the OPIS E85 Conversion Clinic. 2007. 


\section{Determining the Retail Pricing of E85}

A key factor in throughput and sales is the retail pricing of E85. To understand if the desired pricing differential between E85 and gasoline is obtainable, the retailer must calculate the retail price of E85 by factoring in the wholesale pricing, transportation charges, taxes, and the required gross margin, as indicted by NREL's model.

Figure 2 shows that E85 sales drop to nearly zero as the price differential between E85 and gasoline are reduced to zero. As indicated on the graph, experienced station owners find that the profits are maximized when the price differential is $20 \%$.

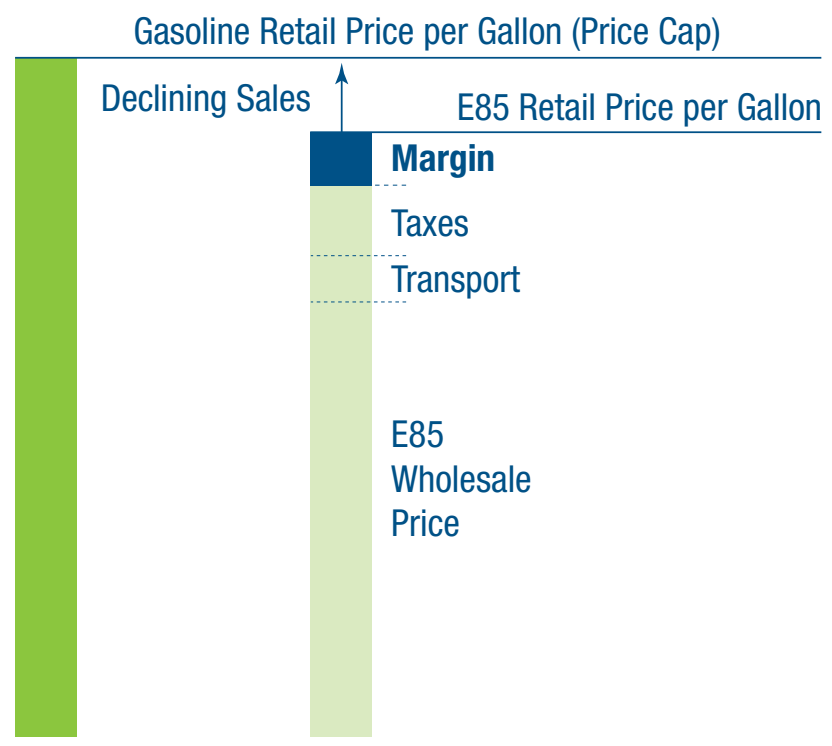

Figure 2. Pricing Differentials of E85 and Gasoline

\section{What's Next?}

Offering E85 can be a profitable venture if all aspects of adding it to a product mix are carefully considered. To learn more about E85 and what it takes to be successful at selling it, download the "E85 Retail Business Case" from the Alternative Fuels and Advanced Vehicles Data Center (AFDC) Web site at www.eere.energy.gov/afdc/fuels/ ethanol_business.html.

Clean Cities coordinators are also available to help. Look up their contact information at www.eere.energy.gov/ cleancities/coordinators.html.

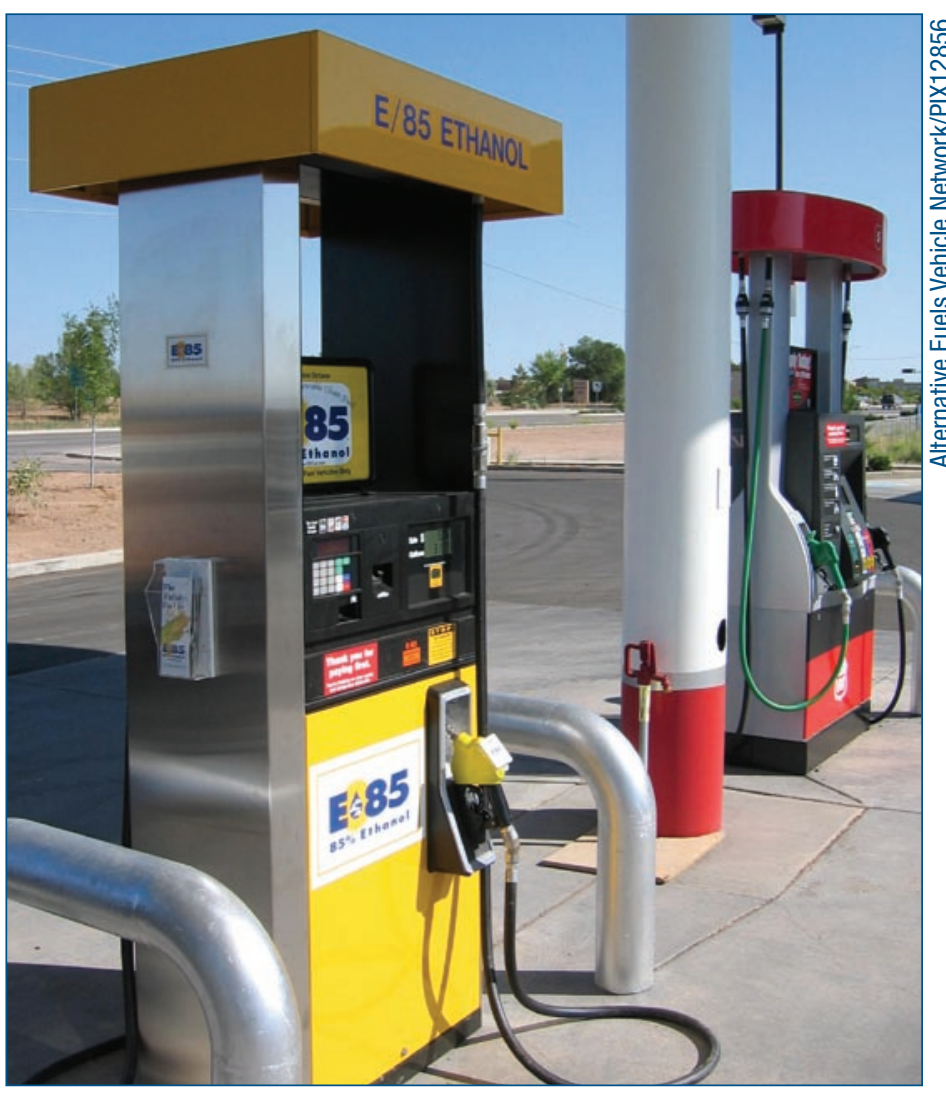

As of January 2008, E85 was available at approximately 1,300 locations throughout the United States. According to the AFDC, this number continues to grow.

\section{Resources}

- "E85 Retail Business Case" www.eere.energy.gov/afdc/fuels/ethanol_business.html

- Alternative Fuels and Advanced Vehicles Data Center www.eere.energy.gov/afdc

- Clean Cities Web site www.eere.energy.gov/cleancities

- E85 Toolkit www.eere.energy.gov/afdc/e85toolkit

- Federal and State Incentives and Laws www.eere.energy.gov/afdc/incentives_laws.html
Sponsored by the U.S. Department of Energy Energy Efficiency and Renewable Energy

Vehicle Technologies Program

For more information contact: EERE Information Center

1-877-EERE-INF (1-877-337-3463) www.eere.energy.gov

Prepared by the National Renewable Energy Laboratory (NREL) NREL is a U.S. Department of Energy National Laboratory

Operated by Midwest Research Institute $\bullet$ Battelle
A Strong Energy Portfolio for a Strong America

Energy efficiency and clean, renewable energy will mean a stronger economy, a cleaner environment, and greater energy independence for America. Working with a wide array of state, community, industry, and university partners, the U.S. Department of Energy's Office of Energy Efficiency and Renewable Energy invests in a diverse portfolio of energy technologies.

DOE/GO-102008-2475 • January 2008

Printed with a renewable-source ink on paper containing at least 50\% wastepaper, including $10 \%$ postconsumer waste. 